\title{
Self-stimulation with monophasic current in the rock squirrel and rat'
}

MARY C. WETZEL, SOUTHERN ARIZONA MENTAL HEALTH CENTER JAMES E. KING, UNIVERSITY OF ARIZONA

Monophasic hypothalamic self-stimulation via bipolar electrodes was compared in four rats and three rock squirrels. During two blocks, the first of four and the second of six test days, response rates for squirrels declined over days unlike those for rats. No evidence was found that differences in electrode loci, tissue injury, or impedance changes contributed to the species difference. When pulse polarity was systematically varied, rates for each current direction differed markedly irrespective of species or interval between successive polarity alternations.

Most data concerned with self-stimulation of the subhuman brain have come from rat experimentation. Direct species comparisons are necessary for positively reinforcing brain stimulation, which has so frequently been called upon to support theories about motivation and emotion, theories which are assumed to have interspecies validity. In the present study the self-stimulation of rats was compared with that of rock squirrels (Citellus variegatus). Rock squirrels are large, diurnal ground squirrels which attain a length of about 11 in., excluding the tail. Identical measures were taken for both species of acquisition of the self-stimulation response, its stability over days, and extinction. Since monophasic current has only rarely been used to obtain selfstimulation via bipolar electrodes, an attempt was made to test its efficacy under different pulse polarities. Method

Ss were four female hooded rats and three female rock squirrels, all adults. The bipolar electrodes were .01 in. diameter stainless steel wires, insulated except at the tips. The general method of implantation has been described previously (Wetzel, 1963). The electrode tip loci were found, at the conclusion of the experiment, to be within the lateral hypothalamus or zona incerta, and there was substantial site overlap between species.

Testing was conducted in a standard Gerbrands rat operant chamber. The stimuli were $.5 \mathrm{msec}$. monophasic pulses delivered at a frequency of 200 per sec. with train duration set at .2 sec. The stimulator setting of 25 volts was not varied and yielded a current of from 170 to $200 \mu$ a. Stimulation intensity appeared to be well within an adequate range, since all Ss gave satisfactory response rates after four or fewer preliminary response-shaping days. During this training E gave manual stimulations by pushing down the bar from outside the box.

After preliminary training, all Ss received 10 days of spaced tests in which at least $48 \mathrm{hr}$. intervened between test days. These 10 test days were divided into two blocks, the first of four and the second of six days, with at least three weeks intervening between blocks. Throughout the 10 test days one and only one pulse polarity was given per day. During the first block, Days 1-4, polarity was not recorded. It was assumed that the particular current direction varied randomly from day to day, since this was determined by the placement on the S's pedestal of two identical leads. During the second block of test days, however, Days 5-10, the hypothesis was tested that different polarities were associated with different reinforcing effects. On test Days 7-10 the polarity sequence over days was $A B B A$. $A$ and $B$ refer to arbitrary designations of the position of cathode and anode for each polarity and corresponded to electrode positions on the pedestals rather than to anatomical structures.

On each of the 10 test days the Ss were given $10 \mathrm{~min}$. of continuous reinforcement self-stimulation followed by $5 \mathrm{~min}$. of extinction (no ICS), and then this session was repeated once. Manual stimulations, up to a maximum of 50 per ICS session, were given by $E$ if $S$ failed to self-stimulate within $.5 \mathrm{~min}$. of being placed in the box, or if it stopped responding for a pause greater than $1 \mathrm{~min}$.

After completion of the spaced test Days 1-10, two further consecutive days of massed tests were given those Ss (S8, S19, R2, R7, and R9) who had responded with different rates to different polarities. During test Days 11 and 12, the sequence of polarities was ABBA followed after $10 \mathrm{~min}$. by $B A A B$. Each polarity condition, A or $B$, consisted of $5 \mathrm{~min}$. of stimulation (manuals given by $\mathrm{E}$ as necessary) followed by $3 \mathrm{~min}$. of extinction.

\section{Resulis}

Figure 1 shows mean free responses per min. over the two daily stimulation sessions for each $S$ during the 10 spaced-polarity test days. Where polarity was recorded it is indicated by the letters, A and $B$. While test Day 1 rates for all squirrels exceeded those for all rats, by Day 4 two (S18 and S19) of the three squirrels had stopped responding entirely. Squirrel 19 consistently put its nose and paws under the bar and pushed up vigorously when $E$ tried to give manual stimulations, which suggested that the ICS had become aversive. No rat, throughout the study, ever failed to self-stimulate.

After a nontesting interval of at least three weeks, it may be seen that Day 5 rates for all Ss, including S18 and S19, exceeded those for Day 4. Again, however, 
nats

SQUinRets
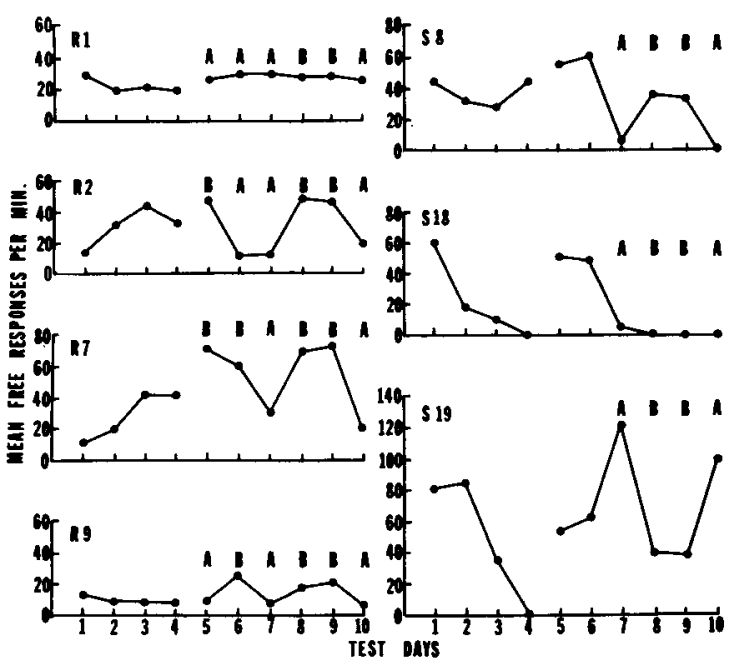

Fig. 1. Mean response rate per day for individual Ss, spaced tests. Letters $A$ and $B$ designate the two polarity conditions.

the squirrels stopped responding for ICSafter a variable number of tests. By test Day 8, S18 gave no free responses, and on Day $10 \mathrm{~S} 8$ failed to respond for the first time. S19 still responded by Day 10, but after the first A session on Day 12 (not shown in Fig.1) it failed to self-stimulate for either polarity.

Rates corresponding to the two polarities may be seen, in Fig. 1, to differ markedly for all Ss except R1 and S18. The substantial polarity effect was also evident during the massed tests on Days 11 and 12, as is indicated by the mean rates in Table 1 . All other measures failed to yield any interspecies differences. No $S$ emitted more than a few extinction responses

Table 1. Response rate per session for each polarity under massed and spaced conditions

\begin{tabular}{lrrrr} 
Subject & \multicolumn{3}{c}{$\begin{array}{c}\text { Mean responses per min. per session } \\
\text { Spaced polarity }\end{array}$} & \multicolumn{2}{c}{$\begin{array}{c}\text { Massed polarity } \\
+\end{array}$} & - \\
\hline R1 & + & - & \multicolumn{2}{c}{ no test } \\
R2 & 28 & 27 & 48 & 23 \\
R7 & 49 & 16 & 60 & 12 \\
R9 & 68 & 23 & 12 & 4 \\
S8 & 18 & 4 & 40 & 12 \\
S18 & 35 & 2 & \multicolumn{2}{c}{ notest } \\
S19 & 2 & 0 & 31 & 22 \\
\hline
\end{tabular}

Note. $+=$ the more reinforcing polarity: $-=$ the less reinforcing polarity by the rate measure. (mean over Ss $=2.5$ per session), and all Ss had to be given manual stimulations to initiate self-stimulation on virtually all days.

\section{Discussion}

Reasons for a cumulative response failure in the squirrels versus sustained self-stimulation in the rats cannot now be given. Several possible sources of the discrepancy, however, seem unlikely. First, there were no discernible, systematic impedance changes over days which might have been associated with stimulus intensity thresholds and response rates. Second, there was overlap between species in the loci of the electrode tips, although a larger sample size would be required to adequately test the hypothesis that locus differences contributed to the apparent species difference. Finally, there was no evidence of excessive cumulative tissue injury. Histological inspection indicated only minimal tissue damage, which was no greater in the seven experimental Ss than in animals which were rejected in preliminary days because of failure to self-stimulate. Current intensity was relatively low, and electrode erosion, as viewed microscopically, was much less than that produced by direct currents of the ma order (Loucks, Weinberg, \& Smith, 1959).

The data on monophasic pulses and bipolar electrodes have few precedents in the literature. Valenstein \& Beer (1961) and Stein (1962) did use the procedure, but apparently a total of only seven Ss, all rats, were tested. The theoretical basis for the widespread use of biphasic symmetrical pulses to minimize injury has as yet been inadequately substantiated by data (Weinman, 1965). Since polarity effects are substantial, their further investigation in self-stimulation studies seems highly justified.

\section{References}

Loucks, R. B., Weinberg, H., \& Smith, M. The erosion of electrodes by small currents. EEG clin. Neurophysiol., 1959, 11, 823-826. Stein, $\mathbf{L}$. An analysis of stimulus-duration preference in self-stimulation of the brain. J. comp. physiol. Psychol., 1962, 55, 405-414.

Valenstein, E. S., \& Beer, B. Unipolar and bipolar electrodes in self-stimulation experiments. Amer J. Physiol., 1961, 201, 1181-1186.

Weinman, J. Biphasic stimulation and electrical properties of metal electrodes. J. appl. Physiol., 1965, 20, 787-790.

Wetzel, Mary C. Self-stimulation aftereffects and runway performance in the rat. $J$. comp. physiol. Psychol., 1963, 56. 673-678.

\section{Note}

1. The data were first reported at Western Psychological Association Convention, April, 1966. 